\title{
CRESCIMENTO E DESEMPENHO DE LINHAGENS DE AVES PESCOÇO PELADO CRIADAS EM SISTEMA SEMI-CONFINADO
}

\author{
Growth and performance of Naked Neck broiler reared in free-range system
}

\author{
Leilane Rocha Barros Dourado', Nilva Kazue Sakomura², Dáphinne Cardoso Nagib do Nascimentoº, \\ Juliano César Dorigam ${ }^{4}$, Simara Márcia Marcato ${ }^{5}$, João Batista Kochenborger Fernandes ${ }^{6}$
}

\begin{abstract}
RESUMO
Este trabalho foi realizado para avaliar o crescimento e desempenho de duas linhagens de aves pescoço pelado. Foram utilizadas 400 aves, distribuídas em um delineamento inteiramente casualizado, os tratamentos consistiram de um esquema fatorial 2 x 2 (linhagens x sexo), com cinco repetições de 20 aves cada. Foram utilizadas aves Pescoço Pelado das linhagens Sasso e ISA Label. As aves receberam rações formuladas à base de milho e de farelo de soja para atender às exigências nutricionais. Foi determinado o ganho de peso (GP), o consumo de ração (CR) e a conversão alimentar (CA) aos 28, 56 e 84 dias de idade e o rendimento de carcaça e de partes aos 84 dias de idade. Não foi observada interação entre sexo e linhagem $(P>0,05)$ para nenhuma das variáveis de desempenho analisadas. Para CR e GP houve diferenças significativas $(\mathrm{P}<0,05)$ entre as linhagens e entre os sexos nos três períodos. As aves da linhagem Sasso apresentaram desempenho superior à ISA Label. Em relação aos parâmetros descritos da equação de Gompertz, as aves da linhagem Sasso apresentaram maior peso à maturidade $(\mathrm{Pm})$ e tempo em que a taxa de crescimento é máxima ( $\left.\mathrm{t}^{*}\right)$ e menor taxa de maturidade (b), indicando que as aves da linhagem ISA Label foram mais precoces para atingir a idade de máximo crescimento. As fêmeas demonstraram melhor aptidão para rendimento de peito e os machos para o rendimento de coxa e de sobracoxa.
\end{abstract}

Termos para indexação: Aves caipira, aves de crescimento lento, curva de crescimento, criação alternativa.

\begin{abstract}
A trial was carried out to evaluate the growth and performance of naked neck birds. Four hundred birds were distributed into four treatments in factorial arrangement (2 strains x 2 genders), with five replicates of 20 birds each. The naked neck strains evaluated were Sasso and ISA Label. The birds were fed a diet formulated with corn and soybean meal according to the nutritional requirements. Food intake, body weight gain and food conversion were determined at 28, 56, and 84 days as well as the yield of carcass and cuts at 84 days. No interaction was observed between gender and strain $(\mathrm{P}>0.05)$. Food intake and body weight gain were different $(\mathrm{P}<0.05)$ between the strains and between the genders. Sasso strain presented higher performance than ISA Label. The parameters estimated for Gompertz equation, the weigh at maturity $(\mathrm{Wm})$ and time that the growth rate is maximum $\left(\mathrm{t}^{*}\right)$ were higher and maturity rate $(\mathrm{b})$ was lower for Sasso strain than those of Isa Label strain. These results indicated that the Isa Label was more precocious than Sasso strain. The females showed better breast yield while the males showed better thigh and drumstick yield.
\end{abstract}

Index terms: Free-range system, growth curve, organic birds, slow-growth broilers.

\section{(Recebido em 27 de fevereiro de 2008 e aprovado em 26 de setembro de 2008)}

\section{INTRODUÇÃO}

A produção de aves criadas em sistemas alternativos tem aumentado consideravelmente nos últimos anos, estando relacionada com o interesse de uma parte dos consumidores por carnes com características diferenciadas das aves criadas convencionalmente. Nesse sentido, as aves caipiras, de acordo com Takahashi et al. (2006), apresentam uma carne mais escura e firme, com sabor acentuado e menor teor de gordura na carcaça.

Para a produção em sistema semi-intensivo é necessário, não apenas o oferecimento de condições ambientais adequadas para as aves, mas, também, a

\footnotetext{
${ }^{1}$ Médica Veterinária, Doutora em Zootecnia - Departamento de Ciência Animal/DCA - Universidade Federal de Piauí - Campus Professora Cinobelina Elvas(CPCE/UFPI) - BR 135, Km 03, Bairro Planalto Horizonte - 64900-000 - Bom Jesus, Piauí - barroslr@yahoo.com.br

2Doutora em Zootecnia - Departamento de Zootecnia/DZ - Faculdade De Ciênicas Agrárias e Veterinárias/(FCAV/UNESP), Universidade Estadual Paulista de Jaboticabal - Via de Acesso Paulo Donato Castellane s/n 14.884.900 - Jaboticabal, SP - sakomura@fcav.unesp.br

${ }_{3}$ Médica Veterinária, Mestre em Zootecnia - Faculdade De Ciênicas Agrárias e Veterinárias/(FCAV/UNESP), Universidade Estadual Paulista de Jaboticabal - Via de Acesso Paulo Donato Castellane s/n 14.884.900 - Jaboticabal, SP - daphinnec@yahoo.com.br;

${ }^{4}$ Aluno de graduação em Zootecnia - Departamento de Zootecnia/DZ - Faculdade De Ciênicas Agrárias e Veterinárias/(FCAV/UNESP), Universidade Estadual Paulista de Jaboticabal - Via de Acesso Paulo Donato Castellane s/n 14.884.900 - Jaboticabal, SP - dorigam@ig.com.br

${ }_{5}^{5}$ Doutora em Zootecnia - Departamento de Zootecnia /DZO - Universidade Estadual de Maringá/UEM - Av. Colombo 5.790, Jd. Universitário - 87020-900 Maringá, PR - simaramm@yahoo.com.br

${ }^{6}$ Zootecnista, Doutor em Aqüicultura - Centro de Aqüicultura/CAUNESP - Centro de Aqüicultura da UNESP de Jaboticabal/CAUNESP - Via de Acesso Paulo Donato Castellane s/n 14.884.900 - Jaboticabal, SP - jbatista@caunesp.unesp.br
} 
utilização de aves melhoradas e adaptadas para o sistema alternativo, com alto potencial genético (Hellmeister Filho, 2002).

De acordo com Zanusso Dionello (2003), seria impossível criar até 12 semanas de idade uma linhagem com crescimento rápido, pois, seu peso seria demasiadamente elevado, sua taxa de engorda excessiva, piorando a conversão alimentar, além de apresentar mortalidade elevada e possíveis problemas locomotores. Por isso, foram estudados genes específicos para o crescimento mais lento e adaptadas para estas características.

O desenvolvimento corporal dos animais com a idade é um fenômeno bastante complexo e pode ser interpretado como sendo um incremento positivo no tamanho e no peso vivo por unidade de tempo, podendo ser visualizado por meio de curvas de crescimento, sendo que para aves, o modelo de Gompertz é o mais adequado (Freitas et al., 1983). A curva de Gompertz permite predizer o peso vivo e taxa de crescimento em qualquer idade de uma ave (Sakomura \& Rostagno, 2007).

Dentre as linhagens existentes no Brasil, podemos citar a Paraíso Pedrês, Caipirão da ESALQ, 7 P, Embrapa 041, Paraíso Pelado, Caipirinha da ESALQ, Carijó Barbadade. Essas aves apresentam características propicias para produção em sistema alternativo, uma vez que são linhagens de crescimento lento e demonstram uma rusticidade ideal para criação ao ar livre.

Conhecer o desempenho das aves é importante para o produtor planejar aspectos diretos ou indiretamente relacionados com a lucratividade da atividade (fornecimento de ração, idade de abate, etc). Dessa forma, torna-se necessária a avaliação das linhagens comerciais atualmente fornecidas para criação em sistema semiconfinado. As informações relacionadas ao crescimento, desempenho, rendimento e qualidade de carcaça dessas linhagens são importantes para o aumento da lucratividade desse sistema de produção.

Conduziu-se este estudo, com o objetivo de determinar os parâmetros da curva de crescimento, avaliar o desempenho zootécnico e o rendimento de carcaça de duas linhagens de frangos pescoço pelado.

\section{MATERIAL E MÉTODOS}

O experimento foi conduzido no Setor de Avicultura do Departamento de Zootecnia da Faculdade de Ciências Agrárias e Veterinárias - FCAV/UNESP, Jaboticabal - SP, de julho a setembro de 2005.

Foram utilizadas 400 aves Pescoço Pelado, sendo 200 aves da linhagem Sasso e 200 da linhagem ISA Label JA57, procedentes da empresa Globoaves.

As aves foram distribuídas em um delineamento experimental inteiramente casualizado, com 4 tratamentos em esquema fatorial $2 \times 2$ (2 linhagens $\mathrm{x} 2$ sexos) e cinco repetições de 20 aves cada. Os tratamentos consistiram em avaliar as linhagens (ISA JA 57 e Sasso) e sexo ( machos e fêmeas).

Os pintos de um dia de idade foram alojados em instalação experimental para sistema semi-confinado, constituída de 20 piquetes, apresentando cada piquete uma área coberta de $3,13 \mathrm{~m}^{2}$ e $72,87 \mathrm{~m}^{2}$ de área para pastejo. Em cada piquete foram colocadas 20 aves. As aves tiveram acesso ao piquete com gramíneas do gênero Paspalum lineu (Poaceae) a partir dos 21 dias de idade.

$\mathrm{Na}$ fase inicial, as aves receberam aquecimento utilizando lâmpadas de infravermelho. As aves foram vacinadas de acordo com manual da linhagem. A ração e água foram fornecidas em comedouros tubulares e bebedouros pendulares. As aves permaneceram na área coberta até os 21 dias de idade, tendo acesso a partir de então à área de pastejo com uma densidade de 3,64 $\mathrm{m}^{2}$ por ave.

As temperaturas máxima e mínima foram registradas diariamente e as médias semanais estão apresentadas na Tabela 1.

As aves foram alimentadas com rações fornecidas adlibitum, compostas principalmente por milho e farelo de soja, e formuladas para atender às exigências das mesmas, conforme programa nutricional recomendado pela empresa Nhô Bento (fornecedora da ração). Os níveis nutricionais das dietas foram de 19,5\% de proteína bruta (PB), $2900 \mathrm{kcal}$ de energia metabolizável (EM), 1,2\% de lisina total (Lis), $0,75 \%$ de aminoácidos sulfurados (AAS), 1,05 de cálcio (Ca) e 0,42 de fósforo disponível (Fd) na fase inicial, de $18,5 \%$ de PB, $2950 \mathrm{kcal}$ de EM, 1,0\% de Lis, 0,65 \% de AAS, $1,0 \%$ de $\mathrm{Ca}$ e $0,40 \%$ de $\mathrm{Fd}$ na fase de crescimento e de

Tabela 1 - Médias das temperaturas máximas e mínimas registradas durante o período experimental.

\begin{tabular}{|c|c|c|c|c|c|c|c|c|c|c|c|c|}
\hline \multirow{2}{*}{$\begin{array}{c}\text { Temperatura } \\
\left({ }^{\circ} \mathrm{C}\right)\end{array}$} & \multicolumn{12}{|c|}{ Semana } \\
\hline & 1 & 2 & 3 & 4 & 5 & 6 & 7 & 8 & 9 & 10 & 11 & 12 \\
\hline Máxima & 32 & 33 & 33 & 30 & 34 & 29 & 35 & 31 & 33 & 27 & 31 & 31 \\
\hline Mínima & 19 & 19 & 20 & 19 & 19 & 18 & 22 & 20 & 20 & 19 & 20 & 19 \\
\hline
\end{tabular}

Ciênc. agrotec., Lavras, v. 33, n. 3, p. 875-881, maio/jun., 2009 
18,0\% de PB, 3000 kcal de EM, 0,9\% de Lis, 0,62 \% de AAS, $1,0 \%$ de $\mathrm{Ca}$ e $0,38 \%$ de $\mathrm{Fd}$ na fase final.

As aves e a ração foram pesadas semanalmente para determinação do peso, do ganho de peso (g/ave), do consumo de ração (g/ave) e da conversão alimentar $(\mathrm{g} / \mathrm{g})$. Os dados foram avaliados aos 28,56 e 84 dias. Ao final do experimento ( 84 dias), três aves de cada parcela experimental com peso próximo ao peso médio obtido por parcela, foram selecionadas e, após jejum de 6 horas foram abatidas para avaliar as características de carcaça: rendimento de carcaça, de peito, de coxa e de sobre-coxa. O rendimento de carcaça foi obtido pela relação entre peso da carcaça fria (sem pés, cabeça e pescoço) e o peso em jejum. O rendimento de peito, coxa, e sobrecoxa foram obtidos pela relação entre o peso dessas partes e o peso da carcaça fria. Todos os valores foram expressos em porcentagem.

As curvas de crescimento e as taxas de crescimento foram obtidas conforme descrito por Sakomura \& Rostagno (2007). Os parâmetros da curva de crescimento foram obtidos pela equação de GOMPERTZ:

$$
\mathrm{Pt}=\mathrm{Pm} \cdot \exp \cdot\left\{-\exp \cdot\left[-\mathrm{b} \cdot\left(\mathrm{t}-\mathrm{t}^{*}\right)\right]\right\}
$$

Onde:

$\mathrm{Pt}=$ peso $(\mathrm{g})$ do animal ao tempo $\mathrm{t}$, expresso em função do Pm; $\mathrm{Pm}=$ peso $(\mathrm{g})$ à maturidade do animal;

$\mathrm{b}=$ taxa de maturidade (por dia);

$\mathrm{t}^{*}=$ tempo (dias) em que a taxa de crescimento é máxima (ponto de inflexão).

As taxas de crescimento (g/dia), foram calculadas por meio da derivada da equação de GOMPERTZ:

$$
\mathrm{TC}=\mathrm{Pm} \cdot \mathrm{b} \cdot\left(\exp \left(-\exp \left(-\mathrm{b} \cdot\left(\mathrm{t}-\mathrm{t}^{*}\right)\right)\right)\right) \cdot\left(\exp \left(-\mathrm{b} \cdot\left(\mathrm{t}-\mathrm{t}^{*}\right)\right)\right)
$$

As análises estatísticas foram realizadas por meio do procedimento GLM do pacote computacional SAS 8.0., segundo o modelo estatístico:

$$
Y i j k=\mu+L i+S j+L x \text { Sij }+ \text { eijk }
$$

\section{RESULTADOS E DISCUSSÃO}

A taxa de mortalidade das aves foi de $0,02 \%$. Os dados de desempenho das aves nas fases de 1 à 28,1 à 56 e 1 à 84 dias de idade, estão apresentados nas tabelas 2, 3 e 4 , respectivamente.

Não foi observada interação entre sexo e linhagem $(\mathrm{P}>0,05)$ em nenhuma das fases, para as variáveis de desempenho analisadas. Para o consumo de ração e ganho de peso nos três períodos (1-28, 1-56 e 1-84 dias) houve diferenças significativas $(\mathrm{P}<0,05)$ entre as linhagens e entre os sexos.

A linhagem Sasso apresentou maior consumo de ração e ganho de peso. Os machos de ambas as linhagens apresentaram maior consumo de ração e ganho de peso.

Para a conversão alimentar houve efeito de sexo apenas nas idades mais avançadas (56 e 84 dias). Os machos demonstraram melhor conversão alimentar, não havendo diferenças significativas $(\mathrm{P}<0,05)$ entre as linhagens. Essa diferenciação apenas acima de 28 dias, pode estar relacionada com a curva de crescimento dos machos e das fêmeas dessa linhagem.

De acordo com Santos et al. (2005), a taxa de crescimento de machos e de fêmeas caipiras é semelhante até os 21 dias de idade e a partir do $28^{\circ}$ dia começa a se diferenciar, os machos apresentam crescimento mais acelerado, com melhor eficiência de utilização do alimento, consequentemente, melhores conversões.

Pode-se considerar ainda que, os machos são favorecidos por aspectos fisiológicos, pois, de acordo com os resultados obtidos por Takahashi et al. (2006), eles apresentam maior comprimento dos intestinos delgado e grosso, o que permite melhor capacidade de absorção de nutrientes, justificando os maiores pesos, rendimento de carcaça e conversão dos machos.

De acordo com Pym (2005), as aves têm sido selecionadas para aumentar a taxa de crescimento e, como consequência lógica, ocorreu aumento do consumo de alimento melhorando a eficiência e antecipando a idade de abate destes animais. Verificase que as aves da linhagem Sasso (linhagem melhorada a partir da Isa label) apresentaram em todas as fases maior consumo de ração e, consequentemente, maior ganho de peso, o que poderia levar a uma redução na idade de abate dessas aves. Entretanto, de acordo com normas do MAPA (Ofício circular $n^{\circ}$ 007/99) a idade de abate de "aves caipiras" não pode ser inferior a 85 dias. Esses aspectos, juntamente com as exigências do mercado consumidor, que geralmente associam a ave caipira como sendo aves de menor peso e conformação, devem ser considerados para a escolha de uma linhagem de crescimento lento em sistema semiconfinado.

Com base nos pesos semanais, foram estimados os parâmetros da equação de Gompertz para cada sexo e linhagens relacionadas na Tabela 5 . 
Tabela 2 - Médias de sexo e de linhagens para as variáveis de ganho de peso (GP), consumo de ração (CR), conversão alimentar (CA) das aves no período de 1 a 28 dias de idade.

\begin{tabular}{|c|c|c|c|c|c|c|c|c|}
\hline \multirow[b]{2}{*}{ Variáveis } & \multirow[b]{2}{*}{ Sexo } & \multicolumn{2}{|c|}{ Linhagem } & \multirow[b]{2}{*}{ Média } & \multicolumn{4}{|c|}{ Probabilidade } \\
\hline & & Sasso & Isa JA57 & & Sexo & Linhagem & $\mathrm{S} \times \mathrm{L}$ & CV (\%) \\
\hline \multirow{3}{*}{$\begin{array}{c}\text { Ganho peso } \\
(\mathrm{g})\end{array}$} & macho & 630 & 575 & $602 \mathrm{~A}$ & & & & \\
\hline & fêmea & 579 & 499 & $539 B$ & $<0,0001$ & $<0,0001$ & 0,082 & 2,60 \\
\hline & Média & $604 a$ & $537 b$ & & & & & \\
\hline \multirow{3}{*}{$\begin{array}{l}\text { Consumo ração } \\
(\mathrm{g})\end{array}$} & macho & 1218 & 1087 & $1153 \mathrm{~A}$ & & & & \\
\hline & fêmea & 1098 & 966 & 1032B & $<0,0001$ & $<0,0001$ & 0,955 & 3,03 \\
\hline & Média & $1158 \mathrm{a}$ & $1027 \mathrm{~b}$ & & & & & \\
\hline \multirow{3}{*}{$\mathrm{CA}$} & macho & 1,934 & 1,891 & 1,916 & & & & \\
\hline & fêmea & 1,897 & 1,935 & 1,912 & 0,878 & 0,929 & 0,120 & 2,84 \\
\hline & Média & 1,916 & 1,913 & & & & & \\
\hline
\end{tabular}

Média seguidas de diferentes letras minúsculas nas linhas e maiúsculas nas colunas diferem estatisticamente pelo teste de Tukey $(\mathrm{P}<0,05)$.

Tabela 3 - Médias de sexo e de linhagens para as variáveis ganho de peso (GP), consumo de ração (CR), conversão alimentar (CA) das aves no período de 1 a 56 dias de idade.

\begin{tabular}{|c|c|c|c|c|c|c|c|c|}
\hline \multirow[b]{2}{*}{ Variáveis } & \multirow[b]{2}{*}{ Sexo } & \multicolumn{2}{|c|}{ Linhagem } & \multirow[b]{2}{*}{ Média } & \multicolumn{4}{|c|}{ Probabilidade } \\
\hline & & Sasso & ISA JA57 & & Sexo & Linhagem & $\mathrm{S} \times \mathrm{L}$ & $\mathrm{CV}(\%)$ \\
\hline \multirow{3}{*}{$\begin{array}{c}\text { Ganho peso } \\
\text { (g) }\end{array}$} & macho & 1801 & 1626 & $1714 \mathrm{~A}$ & & & & \\
\hline & fêmea & 1513 & 1335 & 1424B & $<0,0001$ & $<0,0001$ & 0,951 & 2,63 \\
\hline & Média & $1657 \mathrm{a}$ & $1481 b$ & & & & & \\
\hline \multirow{3}{*}{$\begin{array}{c}\text { Consumo ração } \\
(\mathrm{g})\end{array}$} & macho & 4232 & 3770 & $4001 \mathrm{~A}$ & & & & \\
\hline & fêmea & 3575 & 3185 & 3380B & $<0,0001$ & $<0,0001$ & 0,4591 & 2,84 \\
\hline & Média & $3903 a$ & $3477 b$ & & & & & \\
\hline \multirow{3}{*}{$\mathrm{CA}$} & macho & 2,350 & 2,318 & $2,334 \mathrm{~B}$ & & & & \\
\hline & fêmea & 2,364 & 2,385 & $2,374 \mathrm{~A}$ & 0,044 & 0,7742 & 0,176 & 1,76 \\
\hline & Média & 2,357 & 2,351 & & & & & \\
\hline
\end{tabular}

Média seguidas de diferentes letras minúsculas nas linhas e maiúsculas nas colunas diferem estatisticamente pelo teste de Tukey $(\mathrm{P}<0,05)$.

Tabela 4 - Médias de sexo e linhagens para as variáveis ganho de peso (GP), consumo de ração (CR), conversão alimentar (CA) de aves no período de 1 a 84 dias de idade.

\begin{tabular}{|c|c|c|c|c|c|c|c|c|}
\hline \multirow[b]{2}{*}{ Variáveis } & \multirow[b]{2}{*}{ Sexo } & \multicolumn{2}{|c|}{ Linhagem } & \multirow[b]{2}{*}{ Média } & \multicolumn{4}{|c|}{ Probabilidade } \\
\hline & & Sasso & ISA JA57 & & Sexo & Linhagem & $\mathrm{S} \times \mathrm{L}$ & $\mathrm{CV}(\%)$ \\
\hline \multirow{3}{*}{$\begin{array}{c}\text { Ganho peso } \\
\text { (g) }\end{array}$} & macho & 2946 & 2653 & 2799A & & & & \\
\hline & fêmea & 2341 & 2105 & 2223B & $<0,0001$ & $<0,0001$ & 0,335 & 2,58 \\
\hline & Média & $2644 a$ & $2379 b$ & & & & & \\
\hline \multirow{3}{*}{$\begin{array}{l}\text { Consumo ração } \\
\text { (g) }\end{array}$} & macho & 8467 & 7522 & $7995 \mathrm{~A}$ & & & & \\
\hline & fêmea & 6934 & 6194 & $6564 \mathrm{~B}$ & $<0,0001$ & $<0,0001$ & 0,319 & 3,05 \\
\hline & Média & 7701a & $6858 b$ & & & & & \\
\hline \multirow{3}{*}{$\mathrm{CA}$} & macho & 2,874 & 2,835 & $2,854 \mathrm{~B}$ & & & & \\
\hline & fêmea & 2,962 & 2,943 & $2,953 \mathrm{~A}$ & 0,008 & 0,2467 & 0,694 & 1,82 \\
\hline & Média & 2,918 & 2,889 & & & & & \\
\hline
\end{tabular}

Média seguidas de diferentes letras minúsculas nas linhas e maiúsculas nas colunas diferem estatisticamente pelo teste de Tukey $(\mathrm{P}<0,05)$. 
Tabela 5 - Estimativa dos parâmetros da equação de Gompertz para o peso das aves das linhagens Sasso e ISA Label, de 1 a 84 dias de idade.

\begin{tabular}{|c|c|c|c|c|}
\hline \multirow[b]{2}{*}{ Parâmetros } & \multicolumn{2}{|c|}{ Sasso } & \multicolumn{2}{|c|}{ ISA Label } \\
\hline & Machos & Fêmeas & Machos & Fêmeas \\
\hline$P_{m}^{1}(g)$ & 4301,00 & 3156,70 & 3874,20 & 2911,30 \\
\hline$b^{2}$ (por dia) & 0,0287 & 0,0306 & 0,0283 & 0,0298 \\
\hline $\mathrm{t}^{* 3}(\mathrm{dias})$ & 49,62 & 44,10 & 49,28 & 45,28 \\
\hline
\end{tabular}

$1-\mathrm{P}_{\mathrm{m}}(\mathrm{kg})=$ peso à maturidade.

$2-\mathrm{b}($ por dia $)=$ taxa de maturidade.

3- $\mathrm{t}^{*}($ dia $)=$ tempo em que a taxa de crescimento é máxima.

Pode-se observar que as aves da linhagem Sasso apresentaram maior peso à maturidade $(\mathrm{Pm})$, comparadas às aves da linhagem ISA Label. $\mathrm{O}$ mesmo aconteceu para a taxa de maturidade (b), assim as aves da linhagem Sasso apresentaram maior curva e taxa de crescimento. No entanto, as aves de ambas as linhagens apresentaram semelhantes idades de máximo crescimento ( $\left.\mathrm{t}^{*}\right)$. Dessa forma, aves da linhagem Sasso apresentaram maior crescimento por apresentarem peso vivo, em torno de $262 \mathrm{~g}$ a mais do que as aves da linhagem ISA Label ao final do período experimental, como pode ser observado na Tabela 4.

Entre sexo, pode-se verificar que os machos apresentaram maior Pm e t* de peso vivo. O contrário aconteceu para taxa à maturidade para peso vivo. Isto indica, que as fêmeas foram mais precoces que os machos para atingirem a idade de máximo crescimento de peso vivo, contudo, os machos apresentaram maior peso na maturidade que as fêmeas.

Os valores de Pm e t*, encontrados neste trabalho, para as linhagens Sasso e ISA Label, foram inferiores aos encontrados por Santos et al. (2005) quando estimaram os parâmetros da equação de Gompertz para as linhagens de crescimento lento Paraíso Pedrês (4764 e 4222g e 44 e 48 dias, respectivamente, para machos e fêmeas) e ISA Label (4320 e 3136g e 52 e 53 dias, respectivamente, para machos e fêmeas). No entanto, Figueiredo et al. (2003) encontraram valores semelhantes ao deste trabalho, quando avaliaram os parâmetros de Gompertz para as linhagens Embrapa 041 (3961g e 49,08 dias) e Label Rouge (3471g e 49,30 dias).

Por meio da derivada das equações de Gompertz para peso vivo, foram obtidas as taxas de crescimento, em gramas de peso por dia, de acordo com a idade das aves. Esses dados estão apresentados na Tabela 6.

Observa-se que houve semelhança entre as linhagens para atingir a taxa máxima de crescimento, houve aumento acelerado até 42 e 49 dias, respectivamente, para fêmeas e machos das duas linhagens, após estas idades, as taxas de crescimento foram reduzidas. No entanto, as aves da linhagem Sasso apresentaram maiores taxas de crescimento. As maiores taxas de crescimento observadas para os machos é decorrente do maior potencial de ganho que estes apresentam em relação às fêmeas, corroborando com os resultados de desempenho apresentados na Tabela 4. A maior capacidade de crescimento inicial dos machos favorece a redução no tempo para atingir peso adequado de abate e, conseqüentemente, resulta em menor idade de abate. As diferenças nas taxas de crescimento começam a diferenciar a partir de 21 dias como observado por Santos et al. (2005).

Figueiredo et al. (2003) observaram que as aves da linhagem Embrapa 041 tiveram maior taxa de crescimento (43,3 g/d aos 56 dias) e Label Rouge (38,5 $\mathrm{g} / \mathrm{d}$ aos 56 dias) foram mais tardias do que as linhagens estudadas. A taxa de crescimento máximo alcançada pelas aves da linhagem Sasso foi de 45, $41 \mathrm{~g} / \mathrm{d}$ aos 49 dias para machos e $35,46 \mathrm{~g} / \mathrm{d}$ aos 42 dias para fêmeas e para as aves da linhagem ISA Label foi de 40,33 g/d aos 49 dias para machos e $31,77 \mathrm{~g} / \mathrm{d}$ aos 42 dias para fêmeas. Estes resultados demonstram que as linhagens de crescimento lento apresentam diferentes curvas de crescimento.

Os dados de rendimento de carcaça, peito, coxa e sobre-coxa, estão apresentados na Tabela 7. Não foi observada interação entre sexo e linhagem $(\mathrm{P}>0,05)$ e nem diferenças significativas $(\mathrm{P}>0,05)$ entre as linhagens para essas variáveis.

Entre os sexos, houve diferenças significativas $(\mathrm{P}<0,05)$ para rendimento de partes. As fêmeas apresentaram melhor rendimento de peito e os machos melhor rendimento de coxa e sobre-coxa. Esses resultados corroboram com outros que avaliaram estas características tanto em aves de crescimento lento como de crescimento rápido (Hellmeister Filho, 2002; Santos et al., 2005; Takahashi et al., 2006). 
Tabela 6 - Taxas de crescimento de peso vivo e da ave depenada de acordo com a idade e sexo de frangos de corte das linhagens Sasso e ISA Label.

\begin{tabular}{ccccc}
\hline Linhagem & \multicolumn{2}{c}{ Sasso } & & ISA Label \\
\hline Idade (dias) & Machos & Fêmeas & 8,52 & Fêmeas \\
\hline 1 & 8,80 & 8,59 & 13,26 & 7,78 \\
7 & 14,03 & 13,38 & 19,72 & 11,98 \\
14 & 21,30 & 19,68 & 26,34 & 17,48 \\
21 & 28,89 & 25,78 & 32,24 & 22,85 \\
28 & 35,75 & 30,77 & 36,72 & 27,31 \\
35 & 41,02 & 34,05 & 39,43 & 30,34 \\
42 & 44,26 & 35,46 & 40,33 & 31,77 \\
49 & 45,41 & 35,16 & 39,65 & 31,71 \\
56 & 44,71 & 33,50 & 37,74 & 30,45 \\
63 & 42,55 & 30,92 & 34,97 & 28,32 \\
70 & 39,40 & 27,81 & 31,70 & 25,68 \\
77 & 35,67 & 24,49 & 28,23 & 22,80 \\
84 & 31,70 & 21,21 & & 19,91 \\
\hline
\end{tabular}

Tabela 7 - Médias obtidas para as variáveis rendimento de carcaça, de peito, de coxa e de sobre coxa (\%) de machos e de fêmeas das linhagens Sasso e ISA JA57.

\begin{tabular}{|c|c|c|c|c|c|c|c|c|}
\hline \multirow[b]{2}{*}{$\begin{array}{c}\text { Variáveis } \\
(\%)\end{array}$} & \multirow[b]{2}{*}{ Sexo } & \multicolumn{2}{|c|}{ Linhagem } & \multirow[b]{2}{*}{ Média } & \multicolumn{4}{|c|}{ Probabilidade } \\
\hline & & Sasso & ISA JA57 & & Sexo & Linhagem & $S \times L$ & $\mathrm{CV}(\%)$ \\
\hline \multirow{3}{*}{ Carcaça } & macho & 73,1 & 70,2 & 71,7 & & & & \\
\hline & fêmea & 73,8 & 72,8 & 73,3 & 0,1187 & 0,0661 & 0,3443 & 3,02 \\
\hline & Média & 73,4 & 71,5 & & & & & \\
\hline \multirow{3}{*}{ Peito } & macho & 24,3 & 25,0 & $24,7 b$ & & & & \\
\hline & fêmea & 27,2 & 26,5 & $26,8 \mathrm{a}$ & 0,0005 & 0,9889 & 0,1815 & 4,28 \\
\hline & Média & 25,77 & 25,76 & & & & & \\
\hline \multirow{3}{*}{ Coxa } & macho & 15,0 & 15,5 & $15,2 \mathrm{a}$ & & & & \\
\hline & fêmea & 13,5 & 13,4 & $13,4 b$ & 0,0001 & 0,5374 & 0,3906 & 4,9 \\
\hline & Média & 14,2 & 14,4 & & & & & \\
\hline \multirow{3}{*}{ Sobrecoxa } & macho & 16,0 & 17,1 & $16,6 \mathrm{a}$ & & & & \\
\hline & fêmea & 15,0 & 14,9 & $14,9 \mathrm{~b}$ & 0,0002 & 0,1840 & 0,0652 & 4,7 \\
\hline & Média & 15,5 & 16,0 & & & & & \\
\hline
\end{tabular}

Média seguidas de diferentes letras minúsculas nas linhas e maiúsculas nas colunas diferem estatisticamente pelo teste de Tukey $(\mathrm{P}<0,05)$.

Um fator considerável tanto no desempenho como no rendimento é o desenvolvimento muscular. De acordo com Madeira (2005) em aves caipiras podem ocorrer alterações na musculatura decorrentes do exercício, podendo manifestar-se mais facilmente nos machos, que nas fêmeas. A mesma autora observou que os machos apresentam maior área e freqüência de fibra glicolíticas (músculo da perna), o que pode estar associado à maior atividade física dos machos e à disponibilidade do alimento ad libitum associada à maior voracidade de consumo em relação às fêmeas, o que, conseqüentemente, permite aos machos manifestar sua precocidade de crescimento. 
Gonzales \& Sartori (2002) ainda consideram os fatores hormonais (andrógeno e estrógenos) fundamentais no processo de síntese de proteína muscular.

García-Vao (1994), citado por Santos et al. (2005) afirmou que a velocidade de crescimento tem influência direta sobre o rendimento de carcaça. Em frangos de crescimento lento, tipo caipira, a porcentagem de carne em relação ao peso da carcaça é maior do que no frango de linhagens comerciais. Os rendimentos de carcaça e de cortes para o frango são características de alto valor econômico. A medida que as aves se tornam mais pesadas, estes rendimentos aumentam (Hellmeister Filho, 2002).

Os trabalhos realizados com linhagens de aves tipo caipira são poucos se comparados com os de frango de corte. Apesar da linhagem Sasso ter sido superior no desempenho em relação à ISA Label JA57, esta última tem maior representatividade de comercialização, e por isso, é importante analisar as exigências de mercado, e verificar se as características obtidas com aquelas aves atendem à preferência dos consumidores. De acordo com os dados obtidos por Coelho et al. (2007), é possível verificar que nem sempre há uma relação direta entre melhor desempenho e melhores características sensoriais da carne (maciez e sabores).

\section{CONCLUSÃO}

A linhagem Sasso apresentou melhor desempenho zootécnico e maior potencial de crescimento do que a ISA Label JA57.

\section{AGRADECIMENTOS}

À empresa Globoaves pela doação das aves e à empresa Nhô Bento pelo fornecimento das rações.

\section{REFERÊNCIAS BIBLIOGRÁFICAS}

COELHO, A.A.D.; SAVINO, V.J.M.; ROSÁRIO, M.F.; SILVA, M.A.N.; CASTILLO, C.J.C.; SPOTO, M.H.F. Nota prévia: características da carcaça e da carne de genótipos de frangos caipiras. Brazilian Journal of Food and Technology, Campinas, v.10, n.1, p.9-15, 2007.

FIGUEIREDO, E.A.P.; AVILA, V.S.; SCHIMIDT, G.S.; BARONI JÚNIOR, W.; COLDEBELLA, A.; PICCININ, I. Curvas de crescimento de linhagens criadas em sistema alternativo. Revista Brasileira de Ciências Avícolas, Campinas, v.5, n.5, p.111, 2003. Suplemento.

FREITAS, A.R.; ALBINO, L.F.; ROSSO, L.A. Estimativas do peso de frangos machos e fêmeas através de modelos matemáticos. Concórdia: Embrapa-CNPSA, 1983. 4p. (Comunicado técnico, 68).

GONZALES, E.; SARTORI, J.R. Crescimento e metabolismo muscular. In: MACARI, M.; FURLAN, R.L.; GONZALES, E. Fisiologia aviária aplicada a frangos de corte. 2.ed. Jaboticabal: Funep, 2002. p.279-298.

HELLMEISTER FILHO, P. Efeitos de fatores genéticos e do sistema de criação sobre o desempenho e rendimento de carcaça de frangos tipo caipira. 2002. 92p. Tese (Doutorado em Agronomia)-Escola Superior de Agricultura "Luiza de Queiroz", Piracicaba, 2002.

MADEIRA, L.A. Morfologia das fibras musculares esqueléticas de frangos de corte criados nos sistemas confinado e semi-confinado. 2005. 64p. Dissertação (Mestrado em Zootecnia)-Universidade Estadual Paulista, Botucatu, 2005.

PYM, R.A.E. Genetic aspects of food intake and food utilization efficiency for growth in chickens. In: AUSTRALIAN POULTRY SCIENCE SYMPOSIUM, 17., 2005, Sydney. Proceedings... Sydney: The World's Poultry Science Association, 2005. p.153-162.

SAKOMURA, N.K.; ROSTAGNO, H.S. Métodos de pesquisa em nutrição de monogástricos. Jaboticabal: Funep, 2007. 283p.

SANTOS, A.L.; SAKOMURA, N.K.; FREITAS, E.R.; FORTES, C.M.S.; CARRILHO, E.N.V.M.; FERNANDES, J.B.K. Estudo do crescimento, desempenho, rendimento de carcaça e qualidade de carne de três linhagens de frango de corte. Revista Brasileira de Zootecnia, Viçosa, v.34, p.1589-1598, 2005.

TAKAHASHI, S.E.; MENDES, A.A.; SALDANHA, E.S.P.B.; PIZZOLANTE, C.C.; PELÍCIA, K.; GARCIA, R.G.; PAZ, I.C.L.A.; QUINTEIRO, R.R. Efeito do sistema de criação sobre o desempenho e rendimento de carcaça de frangos de corte tipo colonial. Arquivo Brasileiro de Medicina Veterinária e Zootecnia, Belo Horizonte, v.58, n.4, p.624-632, 2006.

ZANUSSO, J.T.; DIONELLO, N.J.L. Produção avícola alternativa: análise dos fatores qualitativos da carne de frangos de corte tipo caipira. Revista Brasileira de Agrociência, Pelotas, v.9, p.191-194, 2003. 